\title{
STATIC MODELING OF THE RESERVOIR FOR ESTIMATE OIL IN PLACE USING THE GEOSTATISTICAL METHOD
}

\author{
Hakimeh AMANIPOOR* \\ Department of Geology, Faculty of Marine Natural Resources, \\ Khorramshahr University of Marine Science and Technology, Khorramshahr, Iran
}

Received 24 May 2019; accepted 22 November 2019

\begin{abstract}
Three-dimensional simulation using geostatistical methods in terms of the possibility of creating multiple realizations of the reservoir, in which heterogeneities and range of variables changes are well represented, is one of the most efficient methods to describe the reservoir and to prepare a 3D model of it and the results have been used as acceptable results in the calculations due to the high accuracy and the lack of smoothing effect in small changes compared to the results of Kriging estimation.

The initial volumetric tests of the Hendijan reservoir in southern Iran were carried out according to the construction model and the petrophysical model prepared by the software and according to the fluid contact levels, and the ratio of net thickness to total thickness in different reservoir zones. The calculations can be distinguished based on the zoning of the reservoir and also on the basis of type of facies. Accordingly, the average volume of fluid in place of the field is calculated in different horizons. The results of the simulation showed that the Ghar reservoir rock has gas and Sarvak Reservoir has the largest amount of oil in place.
\end{abstract}

Keywords: reservoir modeling, static model, geostatistics, cut off, oil in place.

\section{Introduction}

Three-dimensional static modeling of the reservoir is used as a tool for the development of reservoirs. The correct decision-making based on different scenarios is possible using reservoir model in order to improve reservoir management and field development plan. The geological modeling of the reservoir (three-dimensional static model) contains a 3D structure of the geological volume (Chambers, Yarus, \& Hird, 2000). A three-dimensional static model is a description of the structure, stratigraphy, and rock properties at a certain time. Various data sources including geophysics, well logging, cores, well testing and production data are used in order to build the reservoir model (Davis, 2002). Static modeling is used to examine the structure of the reservoir, rock and fluid properties in order to calculate the volume of hydrocarbons. Then, the volume of recyclable fluid is estimated with the dynamic modeling, and the performance of reservoir production is predicted. This model proposes options for the production scenario, the location of the new wells, and the study of the enhanced oil recovery (Davis, 2002).
The comprehensive reservoir modeling consists of four processes as follows:

- Geophysical interpretation of the reservoir (structure, fault, etc.);

- Geological modeling of the reservoir;

- Petrophysical interpretation and modeling of the reservoir (porosity, permeability, saturation);

- Simulation of flow in the reservoir and production prediction.

The schematic of the four processes has been shown in Figure 1. Interpreting the source of different data and integrating them leads to a more detailed model.

Static modeling of the reservoir based on geostatistical methods including the sequential Gaussian simulation (SGS) method for estimating parameters is used. Considering the lack of data, it was tried to model the hearthogenesis of the reservoir rock using the sequential Gaussian simulation (SGS) technique. In this method, we try to maintain the parameters of frequency distribution and variogram parameters by random selection from the cumulative distribution curve (Farzadi, 2006).

*Corresponding author. E-mail: h_amanipoor@yahoo.com 


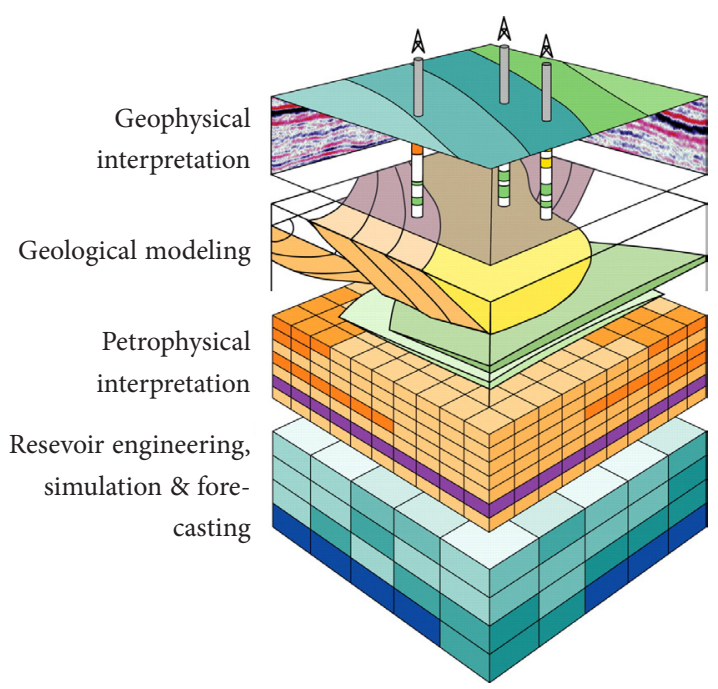

Figure 1. Static modeling processes of the reservoir

Various researchers have studied static models of hydrocarbon reservoirs, including the following.

Abdideh and Ameri (2019) reviewed the methods for determining rock-types in reservoir formations and comparing different methods. They have considered rock groups as a direct relationship between geology, petrophysics and static rock-types (SRT) that, as a homogeneous petrophysical and geological tock-type, there is a special relationship between porosity, permeability and water saturation. In their research, they reviewed the conventional clustering techniques (Lucia, Pittman, RQI, FZI) based on geological, petrophysical features in the scale of cores and $\log$ (Abdideh \& Abyat, 2012).

It is difficult to determine the rock species and exactly model the reservoir in the carbonate formations due to the high heterogeneity (Flugel, 2004).

\section{The importance of research}

Choosing a suitable reservoir development plan and deciding to improve reservoir management requires the use of a realistic description of the reservoir. For the development of a field, estimates of oil in place of the reservoir and the recyclable content are important factors for decision making. Reservoir modeling is an effective method for estimating reservoir parameters and initial evaluation necessities. Since the reservoir data source is within well area, it is necessary to use geostatistical methods to estimate reservoir properties between wells. Geostatistical methods are used to describe the reservoir and create a realistic model for the basis of the reservoir development plan. Because of the spatial structure of petrophysical properties of the reservoir, such as porosity and permeability, the use of geostatistical techniques is necessary to describe this spatial communication space and spatial correlation (Abdideh \& Bargahi, 2012). The construction of the reservoir model consists of two stages of construction modeling and petrophysical modeling of the reservoir, in which the reservoir properties are distributed by the geostatistical methods in the structure of the reservoir (Flugel, 2004). Deterministic methods (such as Kriging) and stochastic (such as sequential guassian) methods are used in order to build the reservoir model. In modeling, it is necessary to integrate data from different sources and use the results of each of them for a model.

The objectives of this research are as follows:

- Modeling of reservoir construction and layering;

- Modeling of porosity reservoir property based on statistical methods;

- Modeling the water saturation reservoir property;

- Investigating the distribution of porosity and saturation characteristics in different directions;

- Estimating the volume of fluid in place in the reservoir model;

- Determining the effect of cut-off on the oil in place of the reservoir.

These goals are done in an integrated process to construct a static geological model of the reservoir based on the geostatistics, and the oil in place volume is calculated after calculating the cut off.

\section{Materials and methods}

Modeling has been done in two structural and petrophysical sections using integration of various data. Reservoir modeling requires knowledge of geological structure and high-quality petrophysical data. Data preparation includes entering well data and seismic data. Petrophysical modeling is performed after constructing a reservoir structural model including layers, headforms and importing equivalent maps.

Petrophysical simulation is carried out based on the sequential Gaussian simulation (SGS), according to the following procedure:

- Estimation of porosity and permeability using data of analysis of cores and different wells in each of the wells studied.

- Plotting a semi-logarithmic porosity-permeability diagram for each reservoir zone and determining the coefficient of correlation and the relationship between porosity and permeability parameters in reservoir zones.

- Construction of the model of field wells.

- Reservoir modeling and networking.

- Data analysis includes the steps of: enlarging, normalizing, deleting the process, and defining the spatial structure (Variogram plotting) for data.

- Preparation of a 3D model of porosity and permeability in the reservoir studied using the sequential Gaussian simulation.

- Preparing maps of the mean porosity and permeability distribution in the reservoir.

- Verification of 3D models plotted (matching between the results of modeling and existing data in wells).

This study was carried out based on well logging diagrams, reports and results of petrophysical assessment of wells. The first stage of the study is the collection of 
geological reports and daily excavation, information of wellhead graphic, petrophysical logs, well digital information, and aberration and azimuth information (CDR). The next step was the introduction of digital petrophysical information of the wells of the field and the column and the stratigraphic comparison diagram of the wells. Further, the preparation and editing of the files required for the reservoir modeling was carried out according to the available information.

\subsection{Three-dimensional modeling of the reservoir}

Conscious development of an oil field should be based on a comprehensive study of the reservoir which involves examining the static and dynamic characteristics of the reservoir which is best presented in the form of a geological model (Olea, 2006). Software such as Petrel and RMS build reservoir models in the world's oil companies, and ultimately provide volumetric calculations for these reservoirs.

Different stages of reservoir modeling in modeling software include structural modeling, facies modeling, gridding and network dimensional changes, petrophysical modeling, model analysis, volume calculation and well planning (Deutsch, 2002).

Existing reservoir modeling software, with high modeling capability and the possibility of generating a variety of models, provides a variety of mathematical and statistical calculations in the best possible way in a geological model with the help of existing data of the reservoir (Sahin, Ghori, \& Ali, 1998). The geological model developed, with all the features of the reservoir and all the information from well drilling to the production and operation of the wells, will be a common model among reservoir engineers and geologists. This model will provide conditions for better management of the reservoir in the future, designing future wells and optimal operation of reservoirs (Kelsall \& Wakefield, 2002). Finally, based on the reservoir production characteristics, an estimate of the volume of oil in the reservoir is presented according to the model which will help authorities in future planning and prioritizing the exploitation of oil reservoirs.

The modeling process in the reservoir studied includes construction modeling, petrophysical modeling and, finally, volumetric analysis by reservoir modeling software. In petrophysical modeling, according to the porosity percentage, especially the water saturation, and also according to the volume calculations, the contribution, the contribution of layers in the storage reservoir is determined. In the case of layers, according to porosity maps and layer water saturation, volume calculations and final estimation of field hydrocarbon storage, decision can be made according to the studies conducted (Abdideh, 2014).

\section{Results and discussion}

The first step in modeling a reservoir is data preparation. The most important input data include seismic data, digital file of underground contour (UGC) map of the well top, digital information of petrophysical charts and aberration and azimuth information. The preparation of well head of well top data files is also other essential input information during the modeling process. It should be noted that the underground contour map is used in the reservoir in the absence of three-dimensional seismic data.

\subsection{Preparation of the structural model}

Typically, preparing structure surfaces are the starting point of a reservoir model. Structure surfaces can be entered directly into the model as an input file or, the mapping tools in an existing software with its gridding capabilities can be used in order to create a surface.

Structural Model begins by entering digital information of well tops, converting them to surfaces, and adjusting them to identified reservoir well tops.

Surface edit/make is done. The maps of the studied horizons have been shown on the horizon of the Ghar in Figure 2, respectively.

Three-dimensional structural gridding of the field is presented at this stage. 3D gridding is in fact a cell set which is created in different directions of the reservoir (length, width, and depth) (Kumar, Vijay, \& MP, 2015).

By performing the above steps, you can use the drawing of longitudinal and transverse sections along the structure and perpendicular to it to know about the continuity of layers. Figure 3 shows the result of the structural modeling process of the entire field.

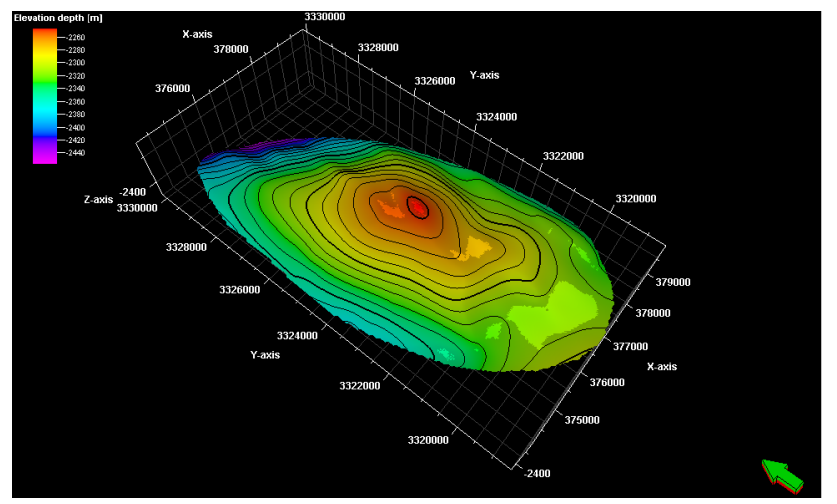

Figure 2. Ghar reservoir horizon plate

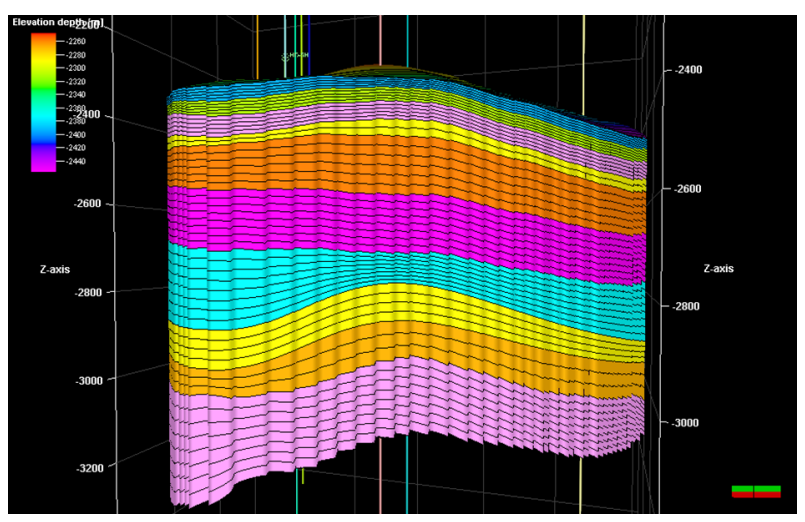

Figure 3. Total structural model in 3D space 


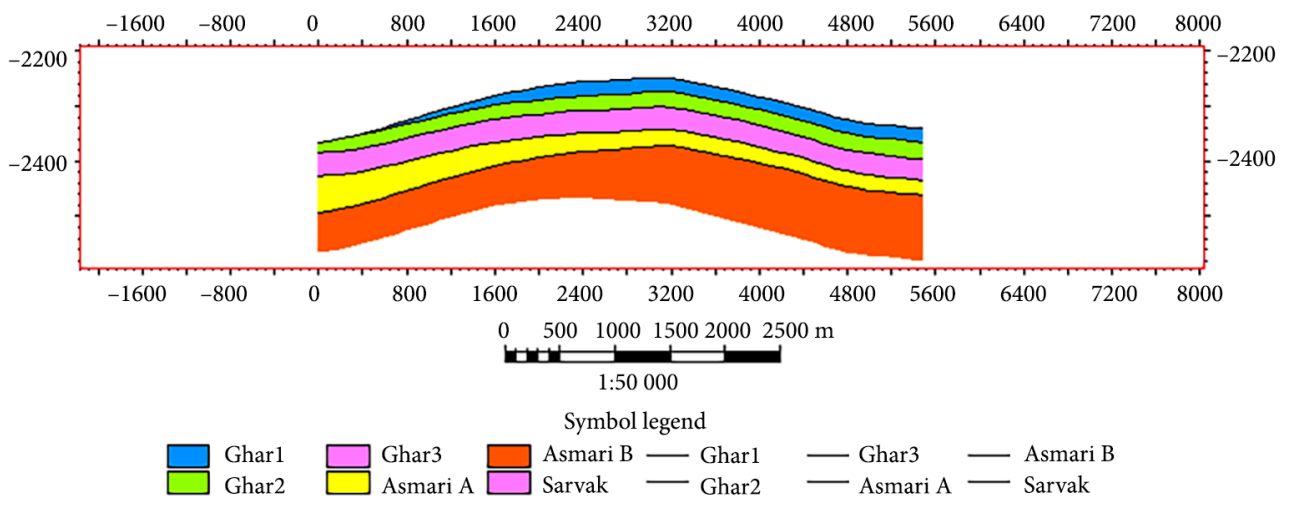

Figure 4. Cross section of the Asmari horizon

The shear sections are used in different direction in order to exactly investigate the structure and the relationship status of horizons and structural slope and status of layers. Figure 4 shows the shear section in the north-south direction of the field for the Asmari horizon.

\subsection{Data analysis}

The two basic conditions for geostatistical calculations (one of the methods of petrophysical modeling) is that, firstly, the data have a normal distribution and, secondly, there is no trend in them (Kumar et al., 2015). The stages of calculation of data transformation and the trend removal were performed on petrophysical data to achieve such conditions. During the data transformation step, data values were truncated and the data normalization was performed. The porosity data transformation step has been shown in the figure for the porosity data of the layers.

The next stage is variogram, in which, based on the available information, the effect of existing data on the generalization of the entire reservoir in three spatial directions can be determined. The variogram is a distance dependent variance which represents the increase in the non-similarity between the data in terms of increase in their distance (Corstange, Grunwald, \& Lark, 2008). In other words, the variogram measures the variation between points of value (location of wells) versus increase of the distance between points (increasing the distance to the well). For example, an example of the variogram stage of the porosity data of the layers has been shown in the figure. It is noted that the non-similarity between points is a function of the heterogeneity of the reservoir and in the normal state, the mean of non-similarity between points increases with increasing distance of points (Farzadi \& Hesthammer, 2007).

The dispersion and generalization of porosity and water saturation data in the entire area of the field can be done according to the adjustments in the three directions $\mathrm{X}, \mathrm{Y}$ and $\mathrm{Z}$ for each layer or all layers at this stage. Analyzed data is used as input data for statistical petrophysical modeling. Data analysis is essential for understanding the distribution of reservoir parameters inside the reservoir.

Figures 5 and 6 respectively show, for example, the results of porosity variography in the Sarvak reservoir horizons and fluid saturation in the Sarvak reservoir horizons.

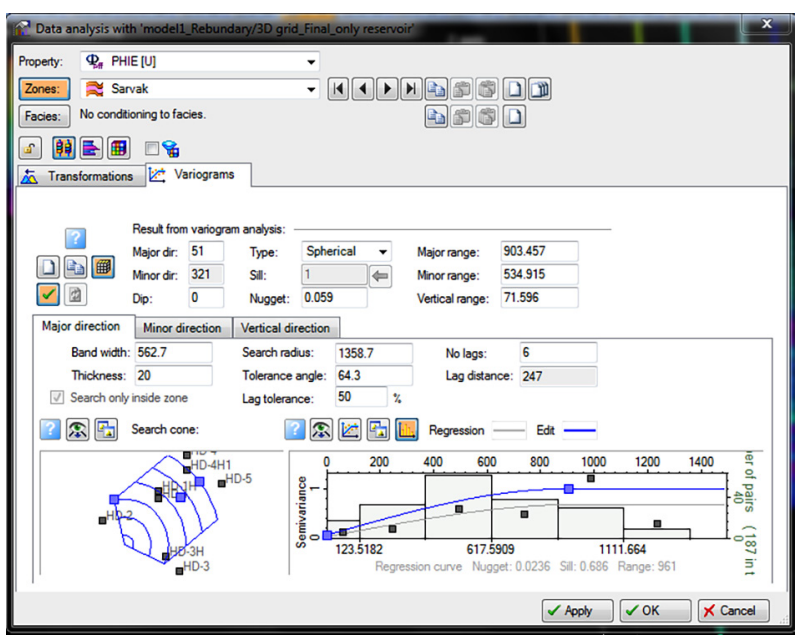

Figure 5. Results of porosity variography on Sarvak reservoir horizon

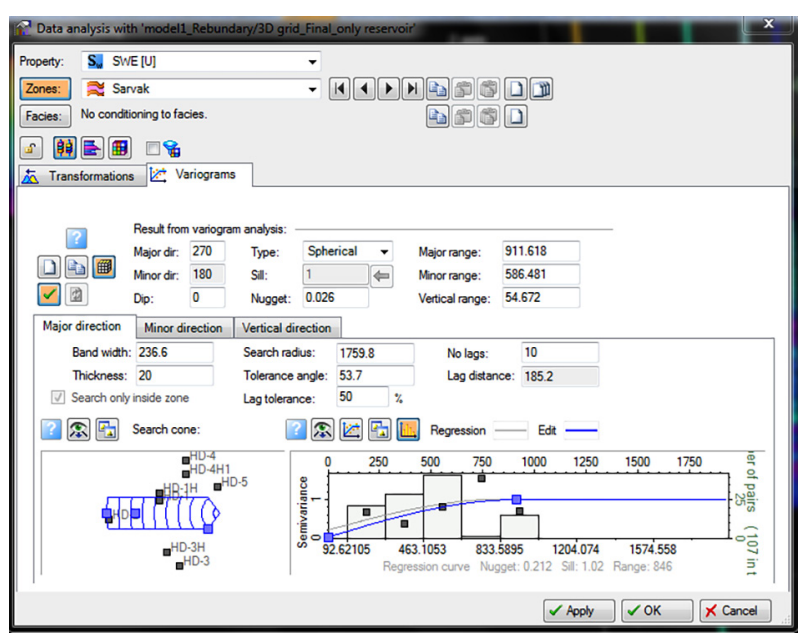

Figure 6. Results of water saturation variography in the Sarvak reservoir horizon 


\subsection{Petrophysical modeling}

Petrophysical modeling examines the important petrophysical properties of the reservoir (porosity and water saturation) that play a role in the production of hydrocarbons from a reservoir. The distribution of porosity and water saturation in different layers of the reservoir along the length, width and depth of the reservoir in three dimensions is used to determine and identify the most suitable locations for the production of hydrocarbons from a reservoir at this stage. The model made in this section plays a significant role in determining the most ideal locations for future production and drilling, saving drilling costs, etc. (Log Interpretation Charts, 2005).

The preparation of each of these structural, facies, and petrophysical models, as well as the accuracy of each of these steps, determines the final accuracy of our estimation of the reservoir. So we have to repeat the modeling process several times and use the most reasonable estimate, which is more consistent with our geological ideas and our knowledge of the reservoir. The geological modeling process has several methods, the method used in the modeling process depends on the type of model and type of data available. Three-dimensional model and specific steps with mathematical and statistical methods for displaying are prepared for each property on which required adjustments have been done. Reservoir modeling software such as RMS and Petrel perform the petrophysical modeling process with two deterministic and stochastic methods. The use of above methods depends on the type of data, the number of wells and the knowledge about the reservoir. The first method creates a simple and fast model based on interpolation of well data by specifying the search radius in three directions which can not be used and only the variation trend of each parameter can be observed in the reservoir. In the geostatistical method method, geostatistics rules are used to predict and simulate reservoir parameters in three dimensions (Zare Khosh Eghbal, Ghazban, Sharifi, \& Khosro Tehrani, 2011).

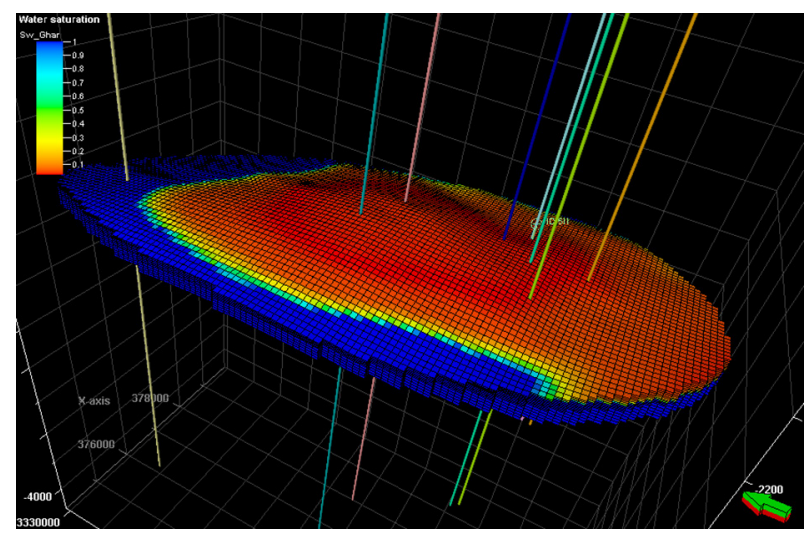

Figure 7. Results of water saturation modeling in Ghar reservoir horizon
It should be noted that the Gaussian Random Function Simulation method is used due to the limited number of wells and data, according to the above, in this section the petrophysical model of porosity and water saturation data has been made for all layers. The results of modeling the fluid saturation and porosity parameters for the Ghar reservoir have been shown in Figures 7 and 8.

\subsection{Volume calculations}

Reservoir volume calculations to estimate the initial volume of oil in place of the reservoir include determination of cut-off values of water saturation and porosity. The cut-off value for porosity is $\mathrm{X} \%$ and for water saturation is $Y \%$. The N/G parameter has been calculated from the NtG_Zone $=$ if $($ PHIE_GRFS $<0.05$ or Sw_Zone $>0.5 .0 .1)$ relationship and calculated in the calculator window. On the basis of the cut-off values and the three-dimensional models of porosity and water saturation provided, Net/ Gross ratio was prepared. Finally, the volume calculations were performed based on the following relationships.

Total reservoir volume:

$$
\text { Bulk }=\text { Structure Volume. }
$$

Useful Reservoir volume:

$$
\text { Net }=\text { Bulk } \times \text { Phi. }
$$

Porous space volume:

$$
\text { Pore }=\text { Net } \times \text { Phi. }
$$

Gas volume of porous space:

$$
\mathrm{HCPV}=\text { Pore }^{\star}(1-\mathrm{Sw}) .
$$

Initial in-situ gas volume:

$$
\mathrm{GIIP}=\mathrm{HCPV} / \mathrm{Bg} \text {. }
$$

The in-situ reservoir volume of year was calculated in three reservoir horizons. For example, for Asmari reservoir, see Table 1.

Finally, the effect of the reservoir cut-off including porosity and fluid saturation was estimated in 20 different scenarios for each of the three reservoir horizons. The results of the Asmari reservoir have been presented in Table 2 for example.

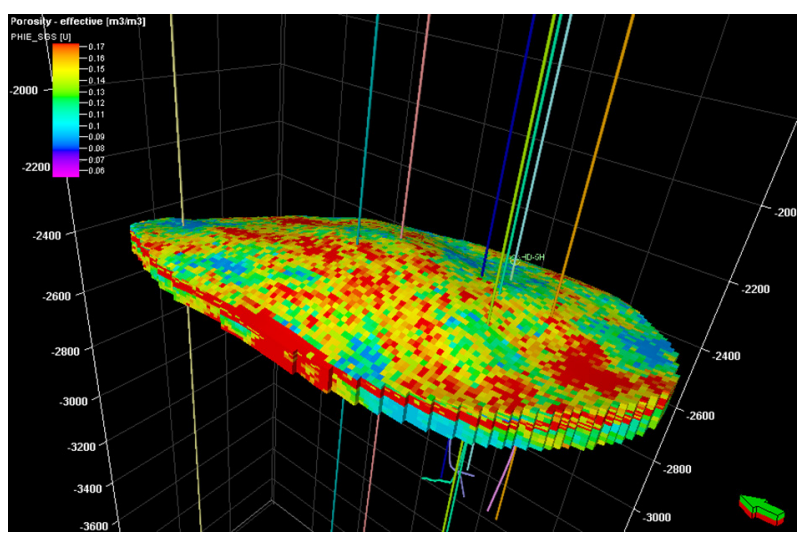

Figure 8. Results of porosity modeling in Ghar reservoir horizon 
Table 1. Estimates of Asmari Zone volume (Base sample)

\begin{tabular}{|c|c|c|c|c|c|}
\hline \multicolumn{2}{|c|}{ Properties in oil interval } & & \\
\hline Sat. water: & \multicolumn{2}{|c|}{ Sw_Asmari } & & \\
\hline Sat. oil: & $1-\mathrm{Sw}-\mathrm{Sg}$ & & & & \\
\hline Sat. gas: & 0 & & $\begin{array}{c}\text { Pore volume } \\
{\left[{ }^{*} 10^{\wedge} 6 \mathrm{rm}^{3}\right]}\end{array}$ & $\begin{array}{c}\text { HCPV oil } \\
{\left[{ }^{*} 10^{\wedge} 6 \mathrm{rm}^{3}\right]}\end{array}$ & $\begin{array}{c}\text { HCPV gas } \\
{\left[{ }^{*} 10^{\wedge} 6 \mathrm{rm}^{3}\right]}\end{array}$ \\
\hline Case & $\begin{array}{c}\text { Bulk volume } \\
{\left[{ }^{*} 10^{\wedge} 6 \mathrm{~m}^{3}\right]}\end{array}$ & $\begin{array}{c}\text { Net volume } \\
{\left[{ }^{*} 10^{\wedge} 6 \mathrm{~m}^{3}\right]}\end{array}$ & 1028 & 1670 & 0 \\
\hline basecase_Asmari & 7146 & 6949 & 171 & 105 & 0 \\
\hline Asmari_A & 1513 & 1472 & 119 & 105 & 0 \\
\hline Asmari_B & 1217 & 1076 & & 0 \\
\hline
\end{tabular}

Table 2. The results of cutoff effect on Asmari Zone volume estimation

\begin{tabular}{|l|c|c|c|c|c|c|c|c|}
\hline & LOOP & SW & pore & $\begin{array}{c}\text { Bulk volume } \\
{\left[{ }^{*} 10^{\wedge} 6 \mathrm{~m}^{3}\right]}\end{array}$ & $\begin{array}{c}\text { Net volume } \\
{\left[{ }^{*} 10^{\wedge} 6 \mathrm{~m}^{3}\right]}\end{array}$ & $\begin{array}{c}\text { Pore volume } \\
{\left[{ }^{*} 10^{\wedge} 6 \mathrm{rm}^{3}\right]}\end{array}$ & $\begin{array}{c}\text { HCPV oil } \\
{\left[{ }^{*} 10^{\wedge} 6 \mathrm{rm}^{3}\right]}\end{array}$ & $\begin{array}{c}\text { HCPV gas } \\
{\left[{ }^{*} 10^{\wedge} 6 \mathrm{rm}^{3}\right]}\end{array}$ \\
\hline basecase_Asmari_2 & 1 & 0.3 & 0.01 & 7146 & 6791 & 1010 & 960 & 0 \\
\hline basecase_Asmari_3 & 2 & 0.336842 & 0.015263 & 7146 & 6820 & 1013 & 962 & 0 \\
\hline basecase_Asmari_4 & 3 & 0.373684 & 0.020526 & 7146 & 6845 & 1016 & 964 & 0 \\
\hline basecase_Asmari_5 & 4 & 0.410526 & 0.025789 & 7146 & 6865 & 1019 & 965 & 0 \\
\hline basecase_Asmari_6 & 5 & 0.447368 & 0.031053 & 7146 & 6886 & 1021 & 967 & 0 \\
\hline basecase_Asmari_7 & 6 & 0.484211 & 0.036316 & 7146 & 6903 & 1023 & 968 & 0 \\
\hline basecase_Asmari_8 & 7 & 0.521053 & 0.041579 & 7146 & 6920 & 1025 & 969 & 0 \\
\hline basecase_Asmari_9 & 8 & 0.557895 & 0.046842 & 7146 & 6934 & 1027 & 969 & 0 \\
\hline basecase_Asmari_10 & 9 & 0.594737 & 0.052105 & 7146 & 6947 & 1028 & 970 & 0 \\
\hline basecase_Asmari_11 & 10 & 0.631579 & 0.057368 & 7146 & 6926 & 1028 & 969 & 0 \\
\hline basecase_Asmari_12 & 11 & 0.668421 & 0.062632 & 7146 & 6818 & 1022 & 963 & 0 \\
\hline basecase_Asmari_13 & 12 & 0.705263 & 0.067895 & 7146 & 6794 & 1021 & 962 & 0 \\
\hline basecase_Asmari_14 & 13 & 0.742105 & 0.073158 & 7146 & 6743 & 1017 & 958 & 0 \\
\hline basecase_Asmari_15 & 14 & 0.778947 & 0.078421 & 7146 & 6726 & 1017 & 957 & 0 \\
\hline basecase_Asmari_16 & 15 & 0.815789 & 0.083684 & 7146 & 6655 & 1011 & 951 & 0 \\
\hline basecase_Asmari_17 & 16 & 0.852632 & 0.088947 & 7146 & 6517 & 999 & 940 & 0 \\
\hline basecase_Asmari_18 & 17 & 0.889474 & 0.094211 & 7146 & 6389 & 988 & 928 & 0 \\
\hline basecase_Asmari_19 & 18 & 0.926316 & 0.099474 & 7146 & 6083 & 958 & 901 & 0 \\
\hline basecase_Asmari_20 & 19 & 0.963158 & 0.104737 & 7146 & 5616 & 911 & 857 & 0 \\
\hline basecase_Asmari_21 & 20 & 1 & 0.11 & 7146 & 5345 & 884 & 825 & 0 \\
\hline
\end{tabular}

\section{Conclusions}

Three-dimensional simulation using geostatistical methods to create the numerous realizations of reservoir in which heterogeneities and variation range of variables well displayed, is one of the most efficient method for reservoir description and preparation of three-dimensional model. And the results are accepted as the results applicable to the calculations due to the high accuracy and the lack of effect of smoothing in small variations compared to the results of the Kriging estimate.

Investigations and studies conducted in this field and the results of 3D simulation of well logging data and modeling the distribution of petrophysical properties of the reservoir showed that:

1. Variogram studies on the reservoir horizons studied provide acceptable results about the properties at the data correlation distance.

2. The results of the simulation showed that the Ghar reservoir has gas also and Sarvak has the largest volume of oil in place.
3. Initial volumetric surveys of Hendijan reservoir were done according to the structural model and petrophysical model prepared by the software and according to the fluid contact surfaces, and the ratio of net thickness to total thickness in different reservoir zones. The initial volume of this reservoir was estimated with the help of a series of formulas. The above calculations are separable based on the zoning of the reservoir and also on the basis of different facies. Accordingly, the average volume of insitu fluid in the horizons has been given in Table 3.

Table 3. Average volume of in-situ fluid in three reservoirs of the Ghar, Asmari and Sarvak in the oil field studied

\begin{tabular}{|l|c|c|c|c|}
\hline Case & $\begin{array}{c}\text { HCPV } \\
\text { oil } \\
{\left[{ }^{*} 10^{\wedge} 6\right.} \\
\left.\mathrm{rm}^{3}\right]\end{array}$ & $\begin{array}{c}\text { Pore } \\
\text { volume } \\
{\left[{ }^{*} 10^{\wedge} 6\right.} \\
\left.\mathrm{rm}^{3}\right]\end{array}$ & $\begin{array}{c}\text { Net } \\
\text { volume } \\
{\left[{ }^{*} 10^{\wedge} 6\right.} \\
\left.\mathrm{m}^{3}\right]\end{array}$ & $\begin{array}{c}\text { Bulk } \\
\text { volume } \\
{\left[{ }^{*} 10^{\wedge} 6\right.} \\
\left.\mathrm{m}^{3}\right]\end{array}$ \\
\hline BaseCase_Ghar & 186 & 250 & 1437 & 1561 \\
\hline basecase_Asmari & 970 & 1028 & 6949 & 7146 \\
\hline Basecase_Sarvak & 3416 & 3883 & 31588 & 34071 \\
\hline
\end{tabular}


4. It is recommended to drill wells in the upper section of the field for better identification of the reservoir structure.

5. Considering the better characteristics of the mideast of the field, it is suggested that future drillings be carried out there.

6. Considering the low porosity in the Sarvak horizon of this field, it is recommended to drill further wells in this part to develop more horizontal wells.

\section{Acknowledgements}

I would like to thank Khorramshahr University of Marine Science and Technology for supporting this work under research grant contract No 155 .

\section{References}

Abdideh, M. (2014). Prediction of mud loss in reservoir rock by geostatistical method. Geomatics, Natural Hazards and Risk, 5, 41-55. https://doi.org/10.1080/19475705.2013.773944

Abdideh, M., \& Abyat, M. (2012). A geostatistical approach for predicting the top producing formation in oil fields. Geodesy and Cartography, 38(3), 111-117.

https://doi.org/10.3846/20296991.2012.728896

Abdideh, M., \& Ameri, A. (2019). Cluster analysis of petrophysical and geological parameters for separating the electrofacies of a gas carbonate reservoir sequence. Natural Resources Research (in press). https://doi.org/10.1007/s11053-019-09533-1

Abdideh, M., \& Bargahi, D. 2012. Designing a 3D model for the prediction of the top of formation in oil fields using geostatistical methods, Geocarto International, 27, 569-579. https://doi.org/10.1080/10106049.2012.662529

Chambers, R. L., Yarus, J. M., \& Hird, K. B. (2000). Petroleum geostatistics for nongeostaticians. Leading Edge Journal, 19(6), 592. https://doi.org/10.1190/1.1438664

Corstange, R., Grunwald, S., \& Lark, R. M. (2008). Inferences from fluctuations in the Local Variogram about the assump- tion of stationary in the variance. Geoderma, 143, 123-132. https://doi.org/10.1016/j.geoderma.2007.10.021

Davis, J. C. (2002). Statistics and data analysis in geology. John Wilry \& Sons.

Deutsch, C. V. (2002). Geostatistical reservoir modeling. Oxford: Oxford University Press.

Farzadi, P., \& Hesthammer, J. (2007). Diagnosis of the Upper Cretaceous paleokarst and turbidite systems from the Iranian Persian Gulf using volume-based multiple seismic attribute analysis and pattern recognition. Petroleum Geoscience, 13, 227-240. https://doi.org/10.1144/1354-079306-710

Farzadi, P. (2006, April). High resolution seismic stratigraphic analysis, an integrated approach to the subsurface geology of the SE Persian Gulf (PhD Thesis). Bergen University.

Felletti, F. (2004). Statistical modeling and validation of correlation in turbidites: an example from the tertiary Piedmont basin. Marine and Petroleum Geology Journal, 21, 23-39. https://doi.org/10.1016/j.marpetgeo.2003.11.006

Flugel, E. (2004). Microfacies of carbonate rocks. Analysis, interpretation and application. New York: Springer-Verlag. https://doi.org/10.1007/978-3-662-08726-8

Kelsall, J., \& Wakefield, J. (2002). Modeling spatial variation in disease risk: A geostatistical approach. Journal of the American Statistical Association, 97, 692-701. https://doi.org/10.1198/016214502388618438

Kumar, S. P., Vijay, R., \& MP, P. (2015). Geostatistical evaluation of groundwater quality distribution of Tonk district, Rajasthan. International Journal of Geomatics and Geosciences, 6(2), 1474-1485.

Log Interpretation Charts. (2005). Schlumberger Company Publication.

Olea, R. A. (2006). A six-step practical approach to semivariogram modeling. Springer-Verlag. https://doi.org/10.1007/s00477-005-0026-1

Sahin, A., Ghori, S. G., \& Ali, A. Z. (1998). Geological controls of variograms in a Complex Carbonate Reservoir, Eastern Province, Saudi Arabia. Mathematical Geology, 30(3). https://doi.org/10.1023/A:1021780915406

Zare Khosh Eghbal, M., Ghazban, F., Sharifi, F., \& Khosro Tehrani, K. (2011). Using geostatistics and GIS to heavy metal pollution zonation in Anzali wetland sediments. Journal of the Earth, 6(19), 33-49 (in Persian). 